\title{
Coverletter
}

\section{Microwave-assisted synthesis, structure and anti-tumor activity of selenized Artemisia sphaerocephala polysaccharide}

\section{Corresponding author: Junlong Wang}

College of Life Science, Northwest Normal University, Lanzhou 730070, People's Republic of China

Bioactive Products Engineering Research Center For Gansu Distinctive Plants, Northwest Normal University, Lanzhou 730070, People's Republic of China

$$
\text { E-mail: nuno-vai@163.com_～Fax: +86-0931-7971414 }
$$

Telephone number: +86-0931-7971999

\section{Co-authors:}

\section{Xiaopin Yang}

College of Life Science, Northwest Normal University, Lanzhou 730070, People's Republic of China

E-mail: 13060729@qq.com

\section{Aijuan Bao}

College of Life Science, Northwest Normal University, Lanzhou 730070, People's Republic of China

$$
\text { E-mail:wyq127127@163.com }
$$

\section{Xinlong Liu}


College of Life Science, Northwest Normal University, Lanzhou 730070, People's Republic of China

E-mail:xlliu@163.com

\section{Junyuan Zeng}

College of Life Science, Northwest Normal University, Lanzhou 730070, People's Republic of China

E-mail: 1622081261@qq.com

\section{Xiurong Liu}

College of Life Science, Northwest Normal University, Lanzhou 730070, People's Republic of China

E-mail:xrliu@sina.com

\section{Jian Yao}

College of Life Science, Northwest Normal University, Lanzhou 730070, People's Republic of China

Bioactive Products Engineering Research Center For Gansu Distinctive Plants, Northwest Normal University, Lanzhou 730070, People's Republic of China E-mail: yaojiani@nwnu.edu.cn

\section{Ji Zhang}

College of Life Science, Northwest Normal University, Lanzhou 730070, People's Republic of China

Bioactive Products Engineering Research Center For Gansu Distinctive Plants, Northwest Normal University, Lanzhou 730070, People's Republic of China 
Key Laboratory of Eco-Environment-Related Polymer Materials Ministry of

Education, College of Chemistry and Chemical Engineering, Northwest Normal University, Lanzhou 730070, People's Republic of China

E-mail: nuno-vai@hotmail.com.cn

\section{Ziqiang Lei}

Key Laboratory of Eco-Environment-Related Polymer Materials Ministry of Education, College of Chemistry and Chemical Engineering, Northwest Normal University, Lanzhou 730070, People's Republic of China

Tel: +86-0931-7971414 Fax: +86-0931-7970686

E-mail: leiziq@nwnu.edu.cn 


\section{Manuscript}

\section{Microwave-assisted synthesis, structure and anti-tumor activity of selenized Artemisia sphaerocephala polysaccharide}

Junlong Wang ${ }^{\mathrm{a}, \mathrm{b}^{*}}$, Xiaopin Yang ${ }^{\mathrm{a}}$, Aijuan Bao ${ }^{\mathrm{a}}$, Xinlong Liu ${ }^{\mathrm{a}}$, Junyuan Zeng ${ }^{\mathrm{a}}$, Xiurong Liu ${ }^{\mathrm{a}}$,

$$
\text { Jian Yao }{ }^{\mathrm{a}, \mathrm{b}}, \text { Ji Zhang }{ }^{\mathrm{a}, \mathrm{b}, \mathrm{c}} \text {, Ziqiang Lei }{ }^{\mathrm{c}}
$$

${ }^{a}$ College of Life Science, Northwest Normal University, Lanzhou 730070, People’s Republic of China

${ }^{\mathrm{b}}$ Bioactive Products Engineering Research Center For Gansu Distinctive Plants, Northwest Normal University,

Lanzhou 730070, People's Republic of China

\footnotetext{
${ }^{\mathrm{c}}$ Key Laboratory of Eco-Environment-Related Polymer Materials Ministry of Education, College of Chemistry and Chemical Engineering, Northwest Normal University, Lanzhou 730070, People’s Republic of China
}

\footnotetext{
* Corresponding author: Junlong Wang Address: College of Life Science, Northwest Normal University, Anning eastroad 967 Lanzhou China

Fax: +86-0931-7971414 e-mail: nuno-vai@163.com
} 


\begin{abstract}
:
In this work, selenylation of Artemisia sphaerocephala polysaccharide (SeASP $\mathrm{MW}_{\mathrm{MW}}$ ) was studied by using $\mathrm{H}_{2} \mathrm{SeO}_{3} / \mathrm{HNO}_{3} / \mathrm{BaCl}_{2}$ reaction system in microwave field. SeASP $\mathrm{MW}_{\mathrm{MW}}$ exhibited the Se content range of 111-264 $\mu \mathrm{g} / \mathrm{g}$ with high yields (72.1-94.9\%). ${ }^{13} \mathrm{C}$ NMR results indicated that the weak C-6 substitution was occurred. The decrease (from $7.348 \times 10^{4} \mathrm{~g} / \mathrm{mol}$ to $\left.1.736-4.667 \times 10^{4} \mathrm{~g} / \mathrm{mol}\right)$ in weight average molecular mass $\left(M_{\mathrm{W}}\right)$ of $\mathrm{SeASP}_{\mathrm{MW}}$ was observed in size exclusion chromatography combined with multi angle laser light scattering (SEC-MALLS) analysis. SeASP $\mathrm{MW}_{\mathrm{MW}}$ exhibited a more rigid solution conformation which might be due to the degradation of polysaccharide chains in acidic reaction reagent. This was also supported by atomic force microscopy (AFM) result that $\mathrm{SeASP}_{\mathrm{MW}}$ showed short chains and island-like topography. In anti-tumor activity assays, SeASP $\mathrm{MW}_{6}$ exhibited the inhibition rates of $32.381 \%$ and $39.776 \%$ against human non-small cell lung cancer cell line (H1650) at the concentration of 100 and 200 $\mu \mathrm{g} / \mathrm{mL}$, respectively. The relatively weak inhibition effect of SeASP $\mathrm{MW}_{\mathrm{w}}$ was not related to cell apoptosis and cell cycle arrest, suggesting Se content might be a key factor to influence the anti-tumor activities of selenized polysaccharides in vitro.
\end{abstract}

Keywords: Selenylation; microwave assisted synthesis; anti-tumor activity 


\section{Introduction}

Selenium (Se) is an essential trace element which can be introduced as inorganic selenium or organic selenium. It is well known that organic selenium compounds exhibit low toxicity and high bioavailability. Reports suggest that selenium as a potential countermeasure against toxicity is mediated via sequestration of toxic elements into biologically inert conjugates and selenium-dependent antioxidant enzymes [1]. Recently, organic selenium compounds such as seleno-proteins and seleno-polysaccharides have emerged as important selenium supplements because selenium is a cofactor of many selenium-dependent enzymes [2]. The metabolism of inorganic selenium or organic selenium is fundamentally different in organism. Organic selenium supplement is reported as reducing the levels of mRNA encoding proteins known to be up-regulated during oxidative stress and cancerous states in animals [3].

Seleno-polysaccharides are organic selenium species with various biological activities. The chemical structure and anti-tumor activities of purified Se-polysaccharides from Se-enriched Ziyang green tea (Se-ZYTP) and Ganoderma lucidum (SeGLP-2B-1) are published. The cell viabilities in human osteosarcoma U-2 OS cells are $31.4 \%$ and $21.2 \%$ for $100 \mu \mathrm{g} / \mathrm{mL}$ and $200 \mu \mathrm{g} / \mathrm{mL}$ in Se-ZYTP treated groups, respectively [4]. SeGLP-2B-1 exhibits an approximately 10-fold stronger anti-proliferative activity against six human cancer cell lines [5]. Mao et al. also report the anti-tumor activity and immunologic function of Se-polysaccharide purified from Se-enriched Grifola frondosathe (Se-GP11). Se-GP11 inhibits the growth of Heps 
tumor in vivo. The increases in thymus index, tumor necrosis factor $\alpha$ (TNF- $\alpha)$ and interleukin-2 (IL-2) levels in serum are observed. The results reveal that Se-GP11 exhibits the anti-tumor activity through improving immunomodulation activities of the tumor bearing mice [6]. Moreover, the biological activities of seleno-polysaccharides are related to antibacterial [7], antioxidant and hypolipidemic activity [8-9], anti-fatigue [10] and immuno-enhancement [11-12]. The structures and biological activities of selenized polysaccharides are one of the most intriguing scientific endeavors in carbohydrate chemistry.

Seleno-polysaccharides can be obtained by extracting from plants, biotransformation and chemical modification of natural polysaccharides. The most commonly employed method is chemical synthesis using $\mathrm{H}_{2} \mathrm{SeO}_{3}$ (or $\mathrm{Na}_{2} \mathrm{SeO}_{3}$ in $\mathrm{HNO}_{3}$ solution) and $\mathrm{Ba}^{2+} / \mathrm{Ca}^{2+}$ as catalyst. However, $\mathrm{H}_{2} \mathrm{SeO}_{3} / \mathrm{HNO}_{3}$ method is time-consuming and not efficient enough to synthesize seleno-polysaccharides with high Se content due to the weak reactivity of $\mathrm{H}_{2} \mathrm{SeO}_{3}$. The most obvious one is its long heating period that may result in degradation of polysaccharide chains in $\mathrm{HNO}_{3}$. For instance, Ji et al. synthesize seleno-Capparis spionosa polysaccharides (Se content of $5.547 \mathrm{mg} / \mathrm{g}$ ) in $\mathrm{H}_{2} \mathrm{SeO}_{3} / \mathrm{HNO}_{3}$ system for $7.5 \mathrm{~h}$ at $71^{\circ} \mathrm{C}$, and Wei et al. (Se content from 1.04 to $3.29 \mathrm{mg} / \mathrm{g}$ ) prefer a long reaction time of $8 \mathrm{~h}$ at $65^{\circ} \mathrm{C}$ [13-14]. Similar results of selenized Atractylodes macrocephala polysaccharides, pectic polysaccharide and garlic polysaccharide with the Se content range of 0.478-29.4 $\mathrm{mg} / \mathrm{g}$ are obtained in the reaction time range of 5-10 $\mathrm{h}[11-12,15]$.

In recent years, the use of microwave heating in chemical reactions has attracted 
a considerable amount of attention, owing to its advantages such as dramatically reduce processing times, increase product yields and enhance product purity or material properties compared to conventionally processed experiments [16-17]. A large number of publications have been reported the application of microwaves in drug synthesis/development [18], organic synthesis [16], polymer chemistry [19], material sciences [20] and carbohydrates chemistry [21]. Several reports have proved that microwaves to a significant extent improve the efficiency in the synthesis of polysaccharides derivatives and polysaccharide-based co-polymers [22-23].

In our previous work, selenized Artemisia sphaerocephala polysaccharides (SeASP) were prepared by using $\mathrm{H}_{2} \mathrm{SeO}_{3} / \mathrm{HNO}_{3}$ system and $\mathrm{Ba}^{2+}$ as catalyst. The $\mathrm{Se}$ content of SeASP varied from 168 to $1703 \mu \mathrm{g} / \mathrm{g}$ depended on the reaction conditions. The substitution position, molecular weight and solution conformation were characterized by employing ${ }^{13} \mathrm{C}$ NMR spectroscopy, size-exclusion chromatograph combined with multi-angle laser light scattering photometer (SEC-MALLS), congo red (CR) spectrophotometric analysis and atomic force microscopy (AFM) observation. After selenylation, SeASP exhibited better scavenge hydroxyl and superoxide radical activities in vitro [24]. In anti-tumor assays, SeASP displayed greater anti-proliferative effects against HepG-2 cells, A549 cells and Hela cells in a dose-dependent manner [25].

In the current study, selenized ASP (SeASP $\left.{ }_{M w}\right)$ was synthesized in microwave field with the irradiation time controlled and all other parameters remain unaltered. Fourier transform infrared spectroscopy (FT-IR), ${ }^{13} \mathrm{C}$ NMR spectroscopy, 
SEC-MALLS were used to study the chemical structure and conformation parameter of SeASP $\mathrm{MW}_{\mathrm{Mw}}$. AFM was employed to observe the shape and size of the polysaccharide molecules. The tumoricidal effects of ASP and SeASP $\mathrm{MW}_{\mathrm{Mw}}$ were evaluated on human non-small cell lung cancer cell line (H1650) in vitro. Furthermore, the apoptotic effect and cell cycle distribution was analyzed by flow cytometry.

\section{Materials and methods}

\subsection{Materials}

Selenious acid $\left(\mathrm{H}_{2} \mathrm{SeO}_{3}\right), \mathrm{HNO}_{3}, \mathrm{BaCl}_{2}, \mathrm{NaOH}$, ascorbic acid and 5-fluorouracil (5-Fu) were purchased from Jingchun Industry Co. Ltd. (Shanghai, China). Dulbecco's modified Eagle medium (DMEM) was obtained from HyClone (GE Healthcare, USA). Fetal bovine serum was supplied by Clark (Australia). Cell counting kit-8 was purchased from Dojindo Laboratories Co. Ltd. (Shanghai, China). RNaseA, TritionX-100, penicillin and streptomycin were obtained from Solarbio Co. Ltd. (Beijing, China). FITC Annexin V apoptosis detection kit containing propidium iodides (PI) staining solution was purchased from Pharmingen (BD Biosciences, USA). All reagents and chemicals were of analytical grade without further purification in this study.

ASP was extracted and purified according to our earlier study. The carbohydrate, protein, and uronic acid contents of ASP were determined to be $90.2 \%, 2.4 \%$ and 16.3\%, respectively. The monosaccharide composition of ASP was L-arabinose, D-xylose, D-mannose, D-glucose and D-galactose (the molar ratio of 
1:4.2:45.9:9.7:11.4) with the weight average molecular mass $\left(M_{\mathrm{W}}\right)$ of $7.348 \times 10^{4}$ $\mathrm{g} / \mathrm{mol}[26]$.

\subsection{Microwave assisted synthesis of selenized ASP (SeASP $\left.P_{M W}\right)$}

ASP (500 mg) was suspended in $50 \mathrm{~mL} \mathrm{HNO}_{3}$ solution (0.8\%). The polysaccharide solution was stirred for $10 \mathrm{~h}$ at room temperature. Then, $\mathrm{H}_{2} \mathrm{SeO}_{3}(1.0 \mathrm{~g})$ and $\mathrm{BaCl}_{2}(1.65 \mathrm{~g})$ were added. Microwave synthesis was carried out in a microwave reaction system (MG08S-2B, Huiyan, Nanjing, China) under open-vessel reflux conditions with a frequency of $2450 \pm 50 \mathrm{MHz}$. To achieve a precise controlling of reaction temperature, microwave irradiation at low microwave power of $300 \mathrm{~W}$ was performed for desired amount of reaction time ranging from 15 to $480 \mathrm{~min}$ at $60^{\circ} \mathrm{C}$ The microwave exposure was paused periodically during the reaction. When reaction was complete, sodium sulfate was added to remove $\mathrm{Ba}^{2+}$ and the $\mathrm{pH}$ value of mixture was adjusted to 7-8 with $\mathrm{NaOH}$ solution $(1 \mathrm{~mol} / \mathrm{L})$. After that, the mixture was dialyzed (molecular weight cutoff 8-12 kDa) against tap water and distilled water until the solution was colorless when ascorbic acid was added. Finally, the mixture was evaporated, precipitated with $\mathrm{EtOH}(95 \%)$ and lyophilized to give $\mathrm{SeASP}_{\mathrm{MW}}$. For comparison, selenylation reaction without $\mathrm{BaCl}_{2}$ was also studied.

Polysaccharide samples were digested in a microwave digestion system (MARS-6, CEM, USA). Selenium content determination was performed by a high-resolution continuum source atomic absorption spectrometer (ContrAA700, Analytical Jena, Germany) equipped with a hydride generator. 


\subsection{FT-IR spectra}

FT-IR analysis was performed on a fourier transform infrared spectrometer (iS10, Thermo Nicolet, USA) with $\mathrm{KBr}$ pellets. Sixteen scans at a resolution of $4 \mathrm{~cm}^{-1}$ were recorded in the wavenumber range of $4000-400 \mathrm{~cm}^{-1}$ and referenced against air.

\section{$2.4{ }^{13}$ C NMR spectra}

${ }^{13}$ C NMR spectroscopy was performed on a Bruker Avance DPX-400 spectrometer, operating at the frequency of $100.593 \mathrm{MHz}$. Samples were deuterium-exchanged several times by freeze drying from $\mathrm{D}_{2} \mathrm{O}$, and then examined in $\mathrm{D}_{2} \mathrm{O}$ with a $5-\mathrm{mm}$ probe at $25^{\circ} \mathrm{C}$. Chemical shifts were reported in ppm using $\mathrm{Me}_{4} \mathrm{Si}$ as the internal reference.

\subsection{Molecular weight and conformation analysis}

Size-exclusion chromatograph combined with multi-angle laser photometer (SEC-MALLS, Wyatt Technology Co., USA) and optilab refractometer (wavelength of $690 \mathrm{~nm})$ were employed to determine the weight average molecular mass $\left(M_{\mathrm{W}}\right)$ and solution conformation of the samples. Polysaccharide solutions were obtained in ultra-pure water with the concentration of $1 \mathrm{mg} / \mathrm{mL}$ at room temperature and filtered through a $0.45 \mu \mathrm{m}$ cellulose filter. The elution of the sample was performed using a Ultrahydrogel $^{\mathrm{TM}}$ column $(7.8 \times 300 \mathrm{~mm}$, Waters, USA) and ultra-pure water as mobile phase at a flow rate of $0.5 \mathrm{~mL} / \mathrm{min}$ with the injection volume of $50 \mu \mathrm{L}$. The refractive 
index increment $(d \mathrm{n} / d \mathrm{c})$ value was determined to be $0.145 \mathrm{~mL} / \mathrm{g}$. The $M_{\mathrm{W}}$ and $\left\langle S^{2}\right\rangle_{\mathrm{z}}$ were calculated using Zimm method. The Astra software (Wyatt Tech. Corp.) was used for data analysis.

\subsection{Molecular morphology observation}

Atomic force microscopy (AFM) measurements were performed using a Nanoscope IIId microscopy (Veeco Instruments, USA) in tapping mode. Commercial RTESP tips were purchased from Bruker (Antimony doped Si) with a nominal spring constant of $40 \mathrm{~N} / \mathrm{m}$ and probe length of $125 \mu \mathrm{m}$ and width of $35 \mu \mathrm{m}$. The bulk solution of sample was dissolved in HPLC grade water and filtered through a $0.45 \mu \mathrm{m}$ cellulose filter. Then, the solution was diluted to 10 and $1 \mu \mathrm{g} / \mathrm{mL}$ with vigorous stirring for $24 \mathrm{~h}$ and placed on a freshly cleaved mica disk and dried in ambient air for $4-8 \mathrm{~h}$ at room temperature. All images were obtained with the resolution of $256 \times 256$ point.

\subsection{Cancer cell proliferation assay}

CCK-8 assay was employed to evaluate the anti-tumor activities of the samples against human non-small cell lung cancer cell line (H1650) in vitro. H1650 cell line was purchased from Gansu Academy of Medical Sciences (Gansu, China). Cells were incubated in $90 \%$ DMEM supplemented with $10 \%$ fetal bovine serum and penicillin-streptomycin (10 units $/ \mathrm{mL})$ at $37^{\circ} \mathrm{C}$ in a humidified atmosphere of $5 \% \mathrm{CO}_{2}$.

H1650 cells were incubated in 96-well plates (the density of $8 \times 10^{3}$ cells per well). 
After cell attachment, the wells were washed and incubated in DMEM for $24 \mathrm{~h}$. Then, cells were treated with serial concentrations of $5-\mathrm{Fu}$ and polysaccharide samples. After $48 \mathrm{~h}, 10 \mu \mathrm{L}$ of CCK-8 was added and cultured for another $1.5 \mathrm{~h}$. The absorbance was read at $450 \mathrm{~nm}$ on a micro-plate enzyme linked immunosorbent assay (ELISA) reader (xMark, BioRad, USA) according to CCK-8 colorimetric procedure. The anti-proliferative activity of samples was calculated as the formula:

Inhibitory rate $(\%)=\left(A_{\text {control }}-A_{\text {treated }}\right) / A_{\text {control }} \times 100 \%$

where $A_{\text {control }}$ and $A_{\text {treated }}$ were the average absorbance of the control and treated group, respectively.

\subsection{Analysis of cell apoptosis and cell cycle distribution}

The apoptosis rate was quantitatively measured by Annexin V-FITC and propidium iodides (PI) double staining. The cell suspension was prepared with a sterile filter screen and washed by cold phosphate buffer saline (PBS) twice and adjusted to the density of $1 \times 10^{6}$ cells/mL. Then, Annexin V-FITC and PI were added and incubated away from light for $15 \mathrm{~min}$ at room temperature. A total of 10,000 cells were collected for each sample. Depending on fluorescence intensity of Annexin VFITC and PI, the populations could be distinguished into double negative (healthy) cells, Annexin-V positive (early apoptotic cells) and double positive (late apoptotic and necroptotic) cells. Stained cells were analyzed by flow cytometry (FACSVerse, USA).

For analyzing cell cycle-phase distribution, H1650 cells was labeled with PI and 
measured by flow cytometry. Briefly, cells were harvested and suspended in PBS, and then fixed overnight at $4^{\circ} \mathrm{C}$ in cold ethanol (70\%). After that, RNase A $(1 \mathrm{mg} / \mathrm{mL})$ was added and incubated for $30 \mathrm{~min}$ at $37^{\circ} \mathrm{C}$. Subsequently, TritionX-100 (2\%) and PI (50 $\mu \mathrm{g} / \mathrm{mL}$ ) were added and incubated away from light for $15 \mathrm{~min}$ at $4^{\circ} \mathrm{C}$. A total of 50,000 cells from each sample were acquired and analyzed. The percentage of cells in each cell cycle phase was estimated by measuring the percentage of remaining cells at $\mathrm{G}_{0} / \mathrm{G}_{1}, \mathrm{~S}$ and $\mathrm{G}_{2} / \mathrm{M}$ phase cells by side scatter analysis.

\subsection{Statistical Analysis}

Results were listed as means \pm standard deviations (S.D.) of three replicates. One way ANOVA was used to analyze the differences between control and treated group by SPSS version 18.0 software. Differences were considered to be statistically significant at $p<0.05$ or $p<0.01$.

\section{Results and discussion}

\subsection{Synthesis of SeASP $P_{M W}$}

In many cases, $\mathrm{H}_{2} \mathrm{SeO}_{3} / \mathrm{HNO}_{3}$ system is selected for the selenylation of polysaccharides in aqueous. In this study, the effect of reaction time on microwave assisted selenylation of ASP was evaluated in aqueous $\mathrm{H}_{2} \mathrm{SeO}_{3} / \mathrm{HNO}_{3}$ solution with or without $\mathrm{BaCl}_{2}$. For a better controlling of reaction temperature, a low microwave power of $300 \mathrm{~W}$ was selected in preparation of $\mathrm{SeASP}_{\mathrm{MW}}$.

Table 1 summarized the data of reaction conditions, yields, Se and carbohydrate 
contents of $\mathrm{SeASP}_{\mathrm{MW}}$. Six selenized derivatives (SeASP $\mathrm{MW1}_{\mathrm{MW}}$ ) with the Se contents of $111-264 \mu \mathrm{g} / \mathrm{g}$ were obtained in the reaction time range of $15-480$ min by using $\mathrm{BaCl}_{2}$ as catalyst in microwave field. It was obvious that a maximum Se content of $264 \mu \mathrm{g} / \mathrm{g}$ in $\mathrm{SeASP}_{\mathrm{Mw} 4}$ was obtained with the increasing of reaction time up to $120 \mathrm{~min}$. Further increasing in the reaction time from 120 to $480 \mathrm{~min}$ did not lead to substantial increments in Se contents of SeASP $\mathrm{MW}_{5}$ and $\mathrm{SeASP}_{\mathrm{MW}}$, which showed the similar values of 235 and $179 \mu \mathrm{g} / \mathrm{g}$, respectively. Reaction times required for microwave heating of SeASP $\mathrm{MW}_{\mathrm{MW}}$ were decreased to about $2 \mathrm{~h}$ compared to the references [11-15]. According to the results from Table 1, the proposed reaction conditions of SeASP $\mathrm{MW}_{\mathrm{MW}}$ in microwave field were reaction time $2 \mathrm{~h}$, reaction temperature $60^{\circ} \mathrm{C}$ and $\mathrm{HNO}_{3}$ concentration of $0.8 \%$. Moreover, we compared the Se contents with our previous result of selenized ASP in the presence of $\mathrm{BaCl}_{2}\left(\mathrm{SeASP}_{\text {cata }}\right)$ using conventional heating method. Under the similar reaction conditions, the Se content of SeASP cata $(969 \mu \mathrm{g} / \mathrm{g})$ was significantly higher than that of SeASP $\mathrm{MW}_{4}$ (Table 1). Selenized ASP using conventional heating method exhibited an approximately 10-fold higher Se contents (the maximum Se content of $1703 \mu \mathrm{g} / \mathrm{g}$ ) compared to $\mathrm{SeASP}_{\mathrm{MW}}$ [24].

It was reported that divalent cation such as $\mathrm{Ba}^{2+}$ or $\mathrm{Ca}^{2+}$ was one of the important parameters in selenylation reaction using $\mathrm{H}_{2} \mathrm{SeO}_{3} / \mathrm{HNO}_{3}$ as selenized reagents [14-15]. The mechanism of $\mathrm{Ba}^{2+}$ as catalyst involved the formation of coordinate barium complexes and enhanced the interaction between hydroxyl groups and $\mathrm{H}_{2} \mathrm{SeO}_{3}$ [24]. In order to assess the Se content of microwave assisted selenylation in a more comprehensive way, SeASP $\mathrm{Mw}_{7}$ was synthesized without $\mathrm{BaCl}_{2}$ as compared with 
$\mathrm{SeASP}_{\mathrm{MW} 4}$ in the same reaction conditions. Unexpectedly, the decrease in Se content

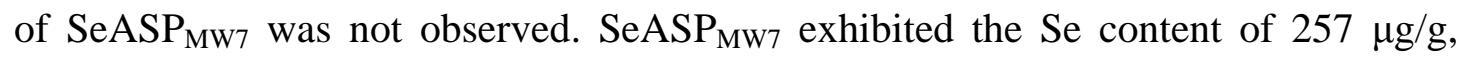

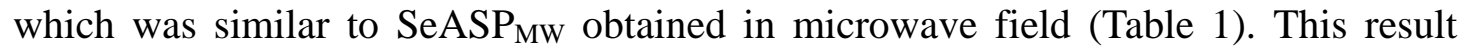
indicated that $\mathrm{Ba}^{2+}$ could not improve the Se content of SeASP $\mathrm{MW}_{\mathrm{M}}$ under microwave irradiation. Such an interpretation was further confirmed by a significant decrease in the Se content of $\operatorname{SeASP}\left(79 \mu \mathrm{g} / \mathrm{g}\right.$ ), which was prepared without $\mathrm{BaCl}_{2}$ using conventional heating method.

In contrast, the yields (72.1-94.9\%) and carbohydrate contents $(77.3-85.4 \%)$ of $\mathrm{SeASP}_{\mathrm{MW}}$ were much higher than the references, such as selenized Schisandra chinensis polysaccharides with the yields of 32.6-54.8\% and carbohydrate contents of 47.2-56.8\% [27], selenized Atractylodes macrocephala polysaccharides with the yields of $19.7-31.7 \%$ and carbohydrate contents of $36.1-63.0 \%$ [12] and selenized garlic polysaccharides with the yields of $14.8-36.1 \%$ and carbohydrate contents of 19.4-50.4\% [11]. The yields of $\mathrm{SeASP}_{\mathrm{Mw}}$ were further comparable to that obtained from selenylation of Radix hedysari polysaccharides (Se-RHP), which showed the yield range of $86.2-94.5 \%$ [14]. Although the Se content was relatively low, selenylation reaction of $\mathrm{SeASP}_{\mathrm{MW}}$ in microwave filed was characterized by time saving and high yields. However, the effect of microwave irradiation in chemical reactions was a combination of many factors such as the thermal and non-thermal effects. The issue of non-thermal effect was still a controversial matter [28]. Thus, further investigation along those directions is necessary to clarify more details in the effect of microwave irradiation on synthesis of selenized polysaccharides under 
different microwave reaction conditions.

\subsection{FT-IR analysis}

Fig. 1A showed the FT-IR spectra of ASP and its selenized derivatives. For ASP, the absorption peaks at 3411.3 and $2928.1 \mathrm{~cm}^{-1}$ were emerged from the stretching vibration of $\mathrm{O}-\mathrm{H}$ and $-\mathrm{CH}_{2-}$ (mainly existed in the backbone of polysaccharide). The peak at $1052.6 \mathrm{~cm}^{-1}$ came from the stretching vibration of $\mathrm{C}-\mathrm{O}$ in hydroxyl groups. These peaks indicated the existence of carbohydrate in ASP. After selenylation, the intensity of the peaks in selenized samples near $2928 \mathrm{~cm}^{-1}$ was decreased. It might be due to the substitution of hydroxyl groups in $\mathrm{SeASP}_{\mathrm{MW} 4}$ and $\mathrm{SeASP}_{\mathrm{Mw} \text {. Compared to }}$ ASP, new peak in selenized sample appeared at $1118.3 \mathrm{~cm}^{-1}$ describing $\mathrm{Se}=\mathrm{O}$ stretching vibration. Moreover, peak at $735.1 \mathrm{~cm}^{-1}$ described C-O-Se stretching vibration [11, 27]. These absorptions indicated that the selenylation had actually occurred

\section{$3.3{ }^{13}$ C NMR analysis}

The ${ }^{13} \mathrm{C}$ NMR spectra of ASP and its selenized derivatives were shown in Fig.

1B-1D. The assignment of the chemical shifts of ASP was shown in our previous study [29]. As shown in Fig. 1B, the resonances in the region near 90-110 ppm of ASP were attributed to the anomeric carbon atoms of arabinofranosyl (Araf, $111.1 \mathrm{ppm}$ ), glucopyranosyl (Glcp, 103.5 ppm), galactopyranosyl (Gal $p, 100.9$ ppm) and mannopyranosyl (Manp, $99.3 \mathrm{ppm}$ ), respectively. In the region of high field near 60 
ppm, the signals at $64.5,62.8$ and 61.5 ppm were assigned to the unlinked C-6 chemical shifts of Gal $p$, Glc $p$ and Man $p$, respectively. Meanwhile, the signals of linked C-6 were shown at 69.8 (Glcp) and 68.1 (Manp) ppm. It was also important to point out that the signal at $178.9 \mathrm{ppm}$ was due to the carboxylate group.

After selenylation, it was found that the ${ }^{13} \mathrm{C}$ NMR spectra of $\mathrm{SeASP}_{\mathrm{MW} 1}$ and SeASP $_{\text {MW4 }}$ were very similar to the native ASP. No significant displacements in the signals range of $65-200 \mathrm{ppm}$ were observed in selenized samples. It could be due to the low Se contents and weak substitution in $\mathrm{SeASP}_{\mathrm{Mw}}$. The signals at 62.3, 60.7 and 59.3 ppm (Fig. 1C-1D) were assigned to the unlinked C-6 chemical shifts of Galp, Glc $p$ and Man $p$ in SeASP $\mathrm{MW}_{\mathrm{M} 1}$ and SeASP $\mathrm{MW}_{\mathrm{M}}$, respectively. New peak at $64.5 \mathrm{ppm}$ of $\mathrm{SeASP}_{\mathrm{MW} 1}$ and $\mathrm{SeASP}_{\mathrm{MW} 4}$ was attributed to the C-6 substituted carbon signal of Manp. It was attributed to the downfield shift of primary carbon (C-6) directly attached to electron-withdrawing $-\mathrm{SeO}_{3}{ }^{-}$groups [30]. However, this $\mathrm{C}-6$ substituted carbon signal in $\mathrm{SeASP}_{\mathrm{MW} 1}$ was very weak owing to the lower Se content compared to $\mathrm{SeASP} \mathrm{Mw}_{\mathrm{Mw}}$. Moreover, a significant decrease in the intensity of the C-6 peak for Man $p$ at 59.3 ppm was observed. Wei et al. also reported that selenized Radix hedysari polysaccharide (Se-RHP3) showed a new peak at $62.8 \mathrm{ppm}$ which was assigned to the O-6 substituted carbons. Meanwhile, C-6 peaks still remained at 60.5 ppm and no obvious decrease in the intensity of C-6 peak was observed [14]. The ${ }^{13} \mathrm{C}$ NMR result confirmed the fact that the weak C-6 substitution was shown in $\mathrm{SeASP}_{\mathrm{MW} 1}$ and SeASP $\mathrm{MW}_{4}$ 


\subsection{Molecular weight and solution conformation analysis}

The SEC-MALLS chromatograms of ASP and SeASP ${ }_{\text {Mw1-6 }}$ were shown in Fig. 2. The values of $M_{\mathrm{W}}$, polydispersity (PD, $\left.M_{\mathrm{W}} / M_{\mathrm{n}}\right)$ and relation equations of the samples were summarized in Table 2. As shown in our previous article, the $M_{\mathrm{W}}$ and polydispersity of ASP was found to be $7.348 \times 10^{4} \mathrm{~g} / \mathrm{mol}$ and 3.184 , respectively [26]. More information about the solution conformation of soluble biopolymer could be determined by the power law describing the $M_{\mathrm{W}}$ dependence of $\left\langle S^{2}\right\rangle_{z}^{1 / 2}$. It was reported by Zhang et al. that a fractal dimension $\left(d_{\mathrm{f}}\right)$ value of 1-1.5 for a rigid rod chain, 1.5-2 for flexible polymer in good solvent, 2-3 for polymers with high degree of branching of compact chain conformation and higher than 3 for globular shape [31-32]. Fig. 2C illustrated the plot of $M_{\mathrm{W}}$ versus $\left\langle S^{2}\right\rangle_{z}^{1 / 2}$ in double logarithmic coordinates. The $d_{\mathrm{f}}$ value of ASP was 2.86 suggesting a conformation between hard sphere and fully swollen branched polymer in aqueous solution.

The SEC-MALLS chromatography and molecular mass distribution of

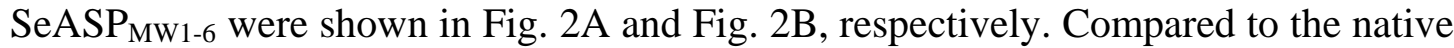
ASP, the decrease in $M_{\mathrm{w}}\left(1.736-4.667 \times 10^{4} \mathrm{~g} / \mathrm{mol}\right)$ with narrow molecular distribution (1.073-2.241) was shown in all selenized samples. No relations between microwave radiation time and $M_{\mathrm{w}}$ were found. The reason for the decreasing in $M_{\mathrm{w}}$ could be explained by the extensive degradation of polysaccharide chains in acid environment. This was in accordance with our earlier report that selenized ASP exhibited a lower $M_{\mathrm{w}}$ range of $1.026-5.407 \times 10^{4} \mathrm{~g} / \mathrm{mol}$ compared to ASP using conventional heating method. The narrow molecular distribution might be due to the loss of small 
molecular mass fractions during dialysis. It could be concluded that the combination of microwave radiation and $\mathrm{H}_{2} \mathrm{SeO}_{3} / \mathrm{HNO}_{3} / \mathrm{BaCl}_{2}$ reaction system also leaded to the degradation of polysaccharide chains in the reaction time range of 15-480 min, which was similar to the references. It had been shown by Wei et al. that chemically selenized Radix hedysari polysaccharide (Se-RHP) showed lower $M_{\mathrm{w}}(27.7-62.7 \mathrm{kDa})$ compared to RHP (84.7 kDa) using $\mathrm{HNO}_{3}-\mathrm{Na}_{2} \mathrm{SeO}_{3}$ method [14]. A sharp decrease in $M_{\mathrm{w}}\left(1.77-10.9 \times 10^{4} \mathrm{~g} / \mathrm{mol}\right)$ was also reported in selenized Potentilla anserina polysaccharide compared to the native one $\left(M_{\mathrm{w}}\right.$ of $\left.22.9 \times 10^{4} \mathrm{~g} / \mathrm{mol}\right)$ by employing $\mathrm{HNO}_{3}-\mathrm{H}_{2} \mathrm{SeO}_{3}$ as reaction reagent [33].

After selenylation, $\mathrm{SeASP}_{\mathrm{MW}}$ showed a decrease in the $d_{\mathrm{f}}$ value according to the power law of $M_{\mathrm{W}}$ versus $\left\langle S^{2}\right\rangle_{z}^{1 / 2}$ (Fig. 2C). As shown in Table 2, the $d_{\mathrm{f}}$ value of

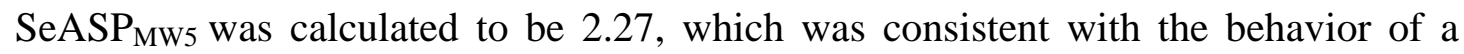
hard sphere and branched macromolecule in aqueous solution. The $d_{\mathrm{f}}$ values of $\mathrm{SeASP}_{\mathrm{MW} 3}$ and $\mathrm{SeASP}_{\mathrm{MW} 4}$ were 1.30 and 1.47 , which exhibited the solution conformation between rigid rod and random coil. It had also been documented that selenized Codonopsis pilosula polysaccharide showed a linear random coil conformation in $0.9 \% \mathrm{NaCl} / 0.02 \% \mathrm{NaN}_{3}$ aqueous solution [15]. In our earlier report using conventional heating method, selenized ASP showed a compact globular conformation in high $M_{\mathrm{W}}$ range $\left(2.268-4.363 \times 10^{4} \mathrm{~g} / \mathrm{mol}\right)$ and a more rigid conformation in low $M_{\mathrm{W}}$ range $\left(1.026-1.426 \times 10^{4} \mathrm{~g} / \mathrm{mol}\right)$. Anionic groups $\left(-\mathrm{SeO}_{2} \mathrm{H}\right)$ had very little influence on $d_{\mathrm{f}}$ values due to the low Se contents $(168-1703 \mu \mathrm{g} / \mathrm{g})$ of selenized samples [25]. Similarly, considering the very low Se contents in $\mathrm{SeASP}_{\mathrm{MW}}$, 
it could also indicated that the more rigid solution conformation of $\mathrm{SeASP}_{\mathrm{MW}}$ was solely governed by low $M_{\mathrm{W}}$. It had been proved that chemically modified polysaccharides (i.e. sulfated polysaccharides) exhibited less flexible conformation, which might be due to the degradation of polysaccharide chains in acidic reaction reagent such as sulfuric acid and chlorosulfonic acid [32, 34]. Polysaccharides having lower molecular weight could readily exhibited a more extended chain conformation. Zhang et al. also reported the formation of ordered aggregates associated with short triple helical chains of lentinan with a low $M_{\mathrm{W}}$ of $5.0 \times 10^{5} \mathrm{~g} / \mathrm{mol}$ [35].

\subsection{Atomic force microscopy (AFM) observation}

In this study, AFM was used to characterize the molecular morphology of selenized samples. The surface morphologies of $\mathrm{SeASP}_{\mathrm{MW} 3}, \mathrm{SeASP}_{\mathrm{MW} 4}$ and SeASP ${ }_{\text {MW6 }}$ with different $M_{\mathrm{W}}$ were observed. AFM images at the concentrations of 10 and $1 \mu \mathrm{g} / \mathrm{mL}$ were shown in Fig. 3 and Fig. 4, respectively. To avoid tip broadening effect, molecular height in section analysis (for linear and tangled molecular morphologies) and particle analysis (for spherical molecular morphology) were employed to measure the size of $\mathrm{SeASP}_{\mathrm{MW}}$.

As presented in Fig. 3A, the molecules of $\mathrm{SeASP}_{\mathrm{MW} 6}$ entangled with each other to form cross-linked pearl-necklace structures. According to the result of section analysis, the molecule height with the average value of approximately $1 \mathrm{~nm}$ was shown. Similarly, SeASP ${ }_{\mathrm{MW} 3}$ showed a morphology of single bead-like chain with the molecule height near 1.5-2 nm (Fig. 3B). This results demonstrated that $\mathrm{SeASP}_{\mathrm{MW}}$ 
with higher $M_{\mathrm{W}}$ exhibited entangled network and aggregation structures in aqueous solution. The morphology of $\mathrm{SeASP}_{\mathrm{MW} 4}$ was less regular in shape as visualized in Fig. 3C, moreover, enhanced aggregation was also observed. When comparing with the molecule size of $\mathrm{SeASP}_{\mathrm{Mw} 6}$ and $\mathrm{SeASP}_{\mathrm{Mw} 3}$, $\mathrm{SeASP}_{\mathrm{Mw} 4}$ with lower $M_{\mathrm{W}}$ adopted spherical morphologies linked with worm-like chains in aqueous solution. The heights of the spherical particles and the short chains and were estimated to be 3 and $1 \mathrm{~nm}$, respectively. As shown in Fig. 3, the formation of aggregates was observed in all of the samples at the concentration of $10 \mu \mathrm{g} / \mathrm{mL}$.

The molecular morphologies (Fig. 4) of the samples were also obtained at a lower concentration of $1 \mu \mathrm{g} / \mathrm{mL}$. As for SeASP $\mathrm{MW}_{\mathrm{MW}}$, the transformation from cross-linked pearl-necklace structures into the spherical morphology and bead-like chains was observed in concentration-dependent AFM images (Fig. 4A). By counting 26 particles, the mean height of the spherical molecules was calculated to be $1.82 \mathrm{~nm}$ in particle analysis. The height profile of the bead-like chains had a height distribution ranging between approximately 0.5 and $0.7 \mathrm{~nm}$ in section analysis. In this case, single molecular morphology of $\mathrm{SeASP}_{\mathrm{MW}}$ was obtained and some aggregations could also be observed. As shown in Fig. 4B, mono-dispersed spherical morphology with a mean height of $1.85 \mathrm{~nm}$ (by counting 37 particles in particle analysis) was observed for $\mathrm{SeASP}_{\mathrm{MW} 3}$, which was similar to the image of $\mathrm{SeASP}_{\mathrm{MW}}$. The topographical AFM image of $\mathrm{SeASP}_{\mathrm{MW} 4}$ appeared an island-like structure and slightly disassociated rod-shaped lumps (Fig. 4C). The molecular height with a mean value of $2.7 \mathrm{~nm}$ was determined in particle analysis. AFM observation was similar to the results obtained 
in Section 3.4 by SEC-MALLS analysis and our previous study in selenized ASP that short chains of $\mathrm{SeASP}_{\mathrm{MW}}$ might be attributed to the lower $M_{\mathrm{W}}$ caused by acid degradation [25]. Moreover, as observed in the molecular morphology of $\mathrm{SeASP}_{\mathrm{Mw}}$, it was deduced that the molecular aggregation was strong at all concentrations. Similar result was reported by Liu et al. that mycelia selenium-polysaccharide (extracted from Catathelasma ventricosum) showed branched chains with the height of $8.5 \mathrm{~nm}$ at the concentration of $1 \mu \mathrm{g} / \mathrm{mL}$, which was consistent with the thickness of the aggregated molecule chains [9]. It had been documented that the aggregation of polysaccharide molecules in AFM analysis was probably due to the hydroxyl groups providing strong inter-molecular and intra-molecular interactions [36].

\subsection{Evaluation of anti-tumor activities in vitro}

To investigate the effects of ASP and its selenized derivatives on the proliferation of cancer cell, H1650 cells were cultivated with different sample concentrations. H1650 cells proliferation in the 5-Fu treated group (positive control) was significantly decreased when compared with control group. The $\mathrm{IC}_{50}$ value of 5-Fu was calculated to be $61.379 \mu \mathrm{g} / \mathrm{mL}$ in the concentrations range of $6.25-100 \mu \mathrm{g} / \mathrm{mL}$ (shown in Supporting file). After incubated with ASP and SeASP $\mathrm{MW1}_{1-6}$ for $48 \mathrm{~h}$ at the concentration range of $25-400 \mu \mathrm{g} / \mathrm{mL}$, the inhibition effects against $\mathrm{H} 1650$ cells were observed and compared with the control group. Fig. 5A showed the growth of H1650 cells in the presence of various samples. However, there was no significant suppressive effect of ASP on the proliferation of H1650 cells at all concentrations. No 
dose-dependency relationship between the inhibition rates and concentrations was observed.

As for selenized samples, CCK-8 assays showed that $\mathrm{SeASP}_{\mathrm{Mw} 2}$, $\mathrm{SeASP}_{\mathrm{Mw} 3}$, $\mathrm{SeASP}_{\mathrm{MW} 4}$ and $\mathrm{SeASP}_{\mathrm{MW}}$ exhibited no proliferation inhibitory activity on $\mathrm{H} 1650$ cells at the concentration range of $25-400 \mu \mathrm{g} / \mathrm{mL}$ (Fig. 5A). It was deserved to note that $\mathrm{SeASP}_{\mathrm{MW} 1}$ exhibited relatively high inhibition rates $(37.965 \%$ and $48.446 \%)$ than ASP $(p<0.01)$ at high concentrations of 300 and $400 \mu \mathrm{g} / \mathrm{mL}$. Compared with ASP and $\mathrm{SeASP}_{\mathrm{MW} 1}$, the anti-proliferation effect was higher in the groups treated with $\mathrm{SeASP}_{\mathrm{MW} 6}$ at all concentrations. The inhibition rates were $32.381 \%$ and $39.776 \%$ at the concentrations of 100 and $200 \mu \mathrm{g} / \mathrm{mL}$, respectively. In our previous work, selenized ASP (Se content of $1703 \mu \mathrm{g} / \mathrm{g}$ ) exhibited enhanced anti-proliferative activity against HepG-2 cells, A549 cells and Hela cells in vitro. The $\mathrm{IC}_{50}$ value was calculated to be $161.6 \mu \mathrm{g} / \mathrm{mL}$ on $\mathrm{A} 549$ cells [25]. However, the $\mathrm{IC}_{50}$ values of $\mathrm{SeASP}_{\mathrm{MW} 1}$ and $\mathrm{SeASP}_{\mathrm{MW} 6}$ could not be determined due to the low inhibition rates $(<$ $50 \%$ ) in the tested concentration range. This results suggested that $\mathrm{SeASP}_{\mathrm{MW}}$ presented relatively low anti-tumor activities against H1650 cells.

It had been reported that some polysaccharides and its derivatives showed anti-tumor activity by inducing cell apoptosis and arresting cell cycle distributions [37-38]. Accordingly, SeASP $\mathrm{MW}_{1}$ and $\mathrm{SeASP}_{\mathrm{MW}}$ were selected to determine the cell apoptosis and cell cycle distribution by flow cytometry (Table 3). Compared to control group, apoptotic cells were not significantly increased in the tumor cells administered with ASP, SeASP $\mathrm{MW}_{1}$ and $\mathrm{SeASP}_{\mathrm{MW} 6}$ at the concentrations of 100 and 
$200 \mu \mathrm{g} / \mathrm{mL}$ (Fig. 5B). Furthermore, the proportion of $\mathrm{G}_{0} / \mathrm{G}_{1}$ phase in ASP treated group increased from $52.75 \%$ to $63.88 \%(p<0.01)$ and $67.18 \%(p<0.05)$ at the concentration of 100 and $200 \mu \mathrm{g} / \mathrm{mL}$, respectively (Fig. 5C). Meanwhile, the DNA content of $\mathrm{H} 1650$ cells in $\mathrm{G}_{2} / \mathrm{M}$ phase was decreased $(p<0.01$ or $p<0.05)$ when compared with the control group. ASP significantly caused H1650 cells arrest at $\mathrm{G}_{0} / \mathrm{G}_{1}$ phase and decreased the cell population of $\mathrm{G}_{2} / \mathrm{M}$ phase, which indicated that DNA synthesis was blocked after $48 \mathrm{~h}$ treatment. However, the cell cycle proportion of $\mathrm{SeASP}_{\mathrm{MW} 1}$ and $\mathrm{SeASP}_{\mathrm{MW} 6}$ was the same as ASP. The concentration dependent manner was not observed in selenized samples (Fig. 5C). Therefore, the relatively weak inhibition effect of $\mathrm{SeASP}_{\mathrm{MW} 1}$ and $\mathrm{SeASP}_{\mathrm{MW} 6}$ was not related to cell apoptosis and cell cycle arrest in H1650 cells.

The ever increasing improvements of biological activities in modified polysaccharides had been often obtained by means of selenylation. It was reported that chemically selenized Capparis spionosa polysaccharide (Se-CSPS) could inhibit the proliferation of human gastric cancer SGC-7901 cells in a dose-dependent manner. The Se content of Se-CSPS was $5547 \mu \mathrm{g} / \mathrm{g}$ with the $\mathrm{IC}_{50}$ value of $111.90 \mu \mathrm{g} / \mathrm{mL}$ [13]. Compared to our previous report, $\mathrm{SeASP}_{\mathrm{Mw}}$ with lower Se contents $(111-264 \mu \mathrm{g} / \mathrm{g})$ presented weaker anti-proliferative activities than selenized ASP with high Se content of $1703 \mu \mathrm{g} / \mathrm{g}$ [25]. Similar result was shown by Mao et al. that Se-enriched Grifola frondosa polysaccharide with a low Se content of $0.5981 \mu \mathrm{g} / \mathrm{g}$ exhibited no anti-tumor activity against HepG-2 cells in vitro [6]. It could be postulate that Se content is a key factor to influence the anti-tumor activities of selenized polysaccharides. However, 
Shang and colleagues showed that Se-containing Ganoderma lucidum polysaccharide (with a similar Se content of $186.7 \mu \mathrm{g} / \mathrm{g}$ as $\mathrm{SeASP}_{\mathrm{MW}}$ ) exhibited significantly higher anti-proliferative activities against human leukemia K562 cells and human breast cancer MCF-7 cells by inducing apoptosis and $\mathrm{G}_{1} / \mathrm{S}$ phase arrest [5, 39]. Wang et al. also offered the evidence that Se-enriched Ziyang green tea polysaccharide with lower Se content of $2.14 \mu \mathrm{g} / \mathrm{g}$ possessed anti-cancer activity in human osteosarcoma U-2 OS cells in vitro and vivo [4]. The possible reason was that the anti-tumor activities of selenized polysaccharides were not a function of a one factor but a multiple action of many factors, such as Se content, substitution patterns and average molecular mass. Further studies on the preparation of selenized polysaccharides with different Se contents and structure features are necessary to expose the structure-bioactivity relations.

\section{Conclusion}

In this work, selenylation of ASP was finished in a short reaction period $(\sim 2 \mathrm{~h})$ with high yields (72.1-94.9\%). SeASP ${ }_{\mathrm{MW}}$ showed the Se content range of 111-264 $\mu \mathrm{g} / \mathrm{g}$. According to the result of ${ }^{13} \mathrm{C}$ NMR analysis, C-6 substitution was shown in

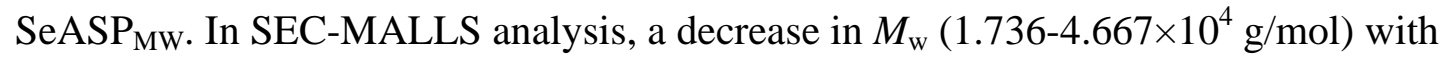
narrow molecular distribution was observed. It could be explained by the extensive degradation of polysaccharide chains in acid environment. Considering the low Se content, a more rigid solution conformation of $\mathrm{SeASP}_{\mathrm{MW}}$ was solely governed by low $M_{\mathrm{W}}$. This was further confirmed by AFM observation that $\mathrm{SeASP}_{\mathrm{Mw}}$ presented short 
chains and island-like topography after selenylation. In anti-proliferative activity assays, the relatively weak inhibition effect of $\mathrm{SeASP}_{\mathrm{MW}}$ was not related to cell apoptosis and cell cycle arrest in H1650 cells. Se content was one of the key factors to influence the anti-tumor activities of selenized polysaccharides.

\section{Acknowledgments}

Financial support of this research from National Science Foundation of China (51463022) and Natural Science Foundation of Gansu Province (1308RJZA200) are gratefully acknowledged. We would also like to thank Prof. Fengyiny Jing (Chang Chun Institute of Applied Chemistry, Chinese Academy of Science) for the measurement of NMR and Prof. Ruibin Guo (The Key Laboratory of Ecological Environment Related Polymer Materials of Ministry of Education, Northwest Normal University) for the use of SEC-MALLS.

\section{List of abbreviations}

Artemisia sphaerocephala polysaccharide, ASP

Selenized Artemisia sphaerocephala polysaccharide, SeASP

Size-exclusion chromatograph combined with multi-angle laser light scattering photometer, SEC-MALLS

Atomic force microscopy, AFM

Selenized ASP synthesized in microwave field, SeASP ${ }_{M W}$

Fourier transform infrared spectroscopy, FT-IR 
Selenious acid, $\mathrm{H}_{2} \mathrm{SeO}_{3}$

Weight average molecular mass, $M_{\mathrm{W}}$

Cell counting kit-8, CCK-8

Propidium iodides, PI

Phosphate buffer saline, PBS

Fractal dimension, $d_{\mathrm{f}}$

\section{References}

[1] I. Zwolak, H. Zaporowska. Selenium interactions and toxicity: a review. Selenium interactions and toxicity. Cell Biol. Toxicol. 28 (2012) 31-46.

[2] W. Thomas. Organoselenium Chemistry Synthesis and Reactions, Wiley-VCH, Weinheim, 2012, pp. 361-363.

[3] S.F. Liao, K.R. Brown, A.J. Stromberg, W.R. Burris, J.A. Boling, J.C. Matthews. Dietary supplementation of selenium in inorganic and organic forms differentially and commonly alters blood and liver selenium concentrations and liver gene expression profiles of growing beef heifers. Biol. Trance Elem. Res. 140 (2011) 151-169.

[4] Y.C. Wang, J. Chen, D.Z. Zhang, Y.F. Zhang, Y.H. Wen, L.H. Li, L.H. Zheng. Tumoricidal effects of a selenium (Se)-polysaccharide from Ziyang green tea on human osteosarcoma U-2 OS cells. Carbohydr. Polym. 98 (2013) 1186-1190.

[5] D.J. Shang, J.N. Zhang, L.Wen, Y. Li, Q. Cui. Preparation, characterization, and antiproliferative activities of the Se-containing polysaccharide SeGLP-2B-1 from Se-enriched Ganoderma lucidum. J. Agr. Food Chem. 57 (2009) 7737-7742. 
[6] G.H. Mao, Y. Ren, Q. Li, H.Y. Wu, D. Jin, T. Zhao, C.Q. Xue, D.H. Zhang, Q.D. Jia, Y.P. Bai, L.Q. Yang, X.Y. Wu. Anti-tumor and immunomodulatory activity of selenium (Se)-polysaccharide from Se-enriched Grifola frondosa. Int. J. Biol. Macromol. 82 (2016) $607-613$.

[7] H.T. Lü, Y.J. Gao, H. Shan, Y.T. Lin. Preparation and antibacterial activity studies of degraded polysaccharide selenide from Enteromorpha prolifera. Carbohydr. Polym. 107 (2014) 98-102.

[8] G.H. Mao, Y. Zou, W.W. Feng, W. Wang, T. Zhao, C.W. Ye, Y. Zhu, X.H. Wu, L.Q. Yang, X.Y. Wu. Extraction, preliminary characterization and antioxidant activity of Se-enriched Maitake polysaccharide. Carbohydr. Polym. 101 (2014) 213-219.

[9] Y.T. Liu, J. Sun, S.Q. Rao, Y.J. Su, J.H. Li, C.M. Li, S.D. Xue, Y.J. Yang. Antidiabetic activity of mycelia selenium-polysaccharide from Catathelasma ventricosum in STZ-induced diabetic mice. Food Chem. Toxicol. 62 (2013) 285-291.

[10] A.P. Chi, H. Li, C.Z. Kang, H.H. Guo, Y.M. Wang, F. Guo, L. Tang. Anti-fatigue activity of a novel polysaccharide conjugates from Ziyang green tea. Int. J. Biol. Macromol. 80 (2015) $566-572$.

[11] Z.Z. Gao, J. Chen, S.L. Qiu, Y.Y. Li, D.Y. Wang, C. Liu, X.P. Li, R.R. Hou, C.J. Yue, J. Liu, H.Q. Li, Y.L. Hu. Optimization of selenylation modification for garlic polysaccharide based on immune-enhancing activity. Carbohydr. Polym. 136 (2016) 560-569.

[12] J. Liu, X. Chen, C.J. Yue, R.R. Hou, Y. Chen, Y. Lu, X.P. Li, R.J. Li, C. Liu, Z.Z. Gao, E.T. Li, Y.Y. Li, H. Wang, Y. Yan, H.Q. Li, Y.L. Hu. Effect of selenylation modification on immune-enhancing activity of Atractylodes macrocephala polysaccharide. Int. J. Biol. 
Macromol. 72 (2015) 1435-1440.

[13] Y.B. Ji, F. Dong, L. Lang, L.W. Zhang, J. Miao, Z.F. Liu, L.N. Jin, Y. Hao. Optimization of synthesis, characterization and cytotoxic activity of seleno-Capparis spionosa L. polysaccharide. Int. J. Mol. Sci. 13 (2012) 17275-17289.

[14] D.F. Wei, T. Chen, M.F. Yan, W.H. Zhao, F. Li, W.D. Cheng, L.X. Yuan. Synthesis, characterization, antioxidant activity and neuroprotective effects of selenium polysaccharide from Radix hedysari. Carbohydr. Polym. 125 (2015) 161-168.

[15] W.X. Chen, J.Y. Chen, H.M. Wu, Y.Q. Gou, F.D. Hua, L.J. Liu, X. Gao, P. Zhang. Optimization of selenylation conditions for a pectic polysaccharide and its structural characteristic. Int. J. Biol. Macromol. 69 (2014) 244-251.

[16] C.O. Kappe. Controlled microwave heating in modern organic synthesis. Angew. Chem. 43 (2004) 6250-6284.

[17] D. Dallinger, C. O. Kappe. Microwave-assisted synthesis in water as solvent. Chem. Rev. 107 (2007) 2563-2591.

[18] V. Santagada, F. Frecentese, E. Perissutti, F. Fiorino, B. Severino, G. Caliendo. Microwave assisted synthesis: a new technology in drug discovery. Mini-Rev. Med. Chem. 9 (2009) $340-358$.

[19] S.L. Pedersen, A.P. Tofteng, L. Malik, K.J. Jensen. Microwave heating in solid-phase peptide synthesis. Chem. Soc. Rev. 41 (2012) 1826-1844.

[20] G.A. Tompsett, W.C. Conner, K. S. Yngvesson. Microwave synthesis of nanoporous materials. Chemphyschem. 7 (2006) 296-319.

[21] H. Wang, Y. Shi, G. Le. Rapid microwave-assisted synthesis of polydextrose and 
identification of structure and function. Carbohydr. Polym. 113 (2014) 225-230.

[22] Meenkashi, M. Ahuja, P. Verma. MW-assisted synthesis of carboxymethyl tamarind kernel polysaccharide-g-polyacrylonitrile: optimization and characterization. Carbohydr. Polym. 113 (2014) 532-538.

[23] M.U. Chhatbar, R. Meena, K. Prasad, D.R. Chejara, A.K. Siddhanta. Microwave-induced facile synthesis of water-soluble fluorogenic alginic acid derivatives. Carbohydr. Res. 346 (2011) 527-33.

[24] J.L. Wang, B.T. Zhao, X.F. Wang, J. Yao, J. Zhang. Synthesis of selenium-containing polysaccharides and evaluation of antioxidant activity in vitro. Int. J. Biol. Macromol. 51 (2012) 987-991.

[25] J.L. Wang, Q.Y. Li, A.J. Bao, X.R. Liu, J.Y. Zeng, X.P. Yang, J. Yao, J. Zhang, Z.Q. Lei. Synthesis of selenium-containing Artemisia sphaerocephala polysaccharides: Solution conformation and anti-tumor activities in vitro. Carbohydr. Polym. 152 (2016) 70-78.

[26] J.L. Wang, J. Zhang, X.F. Wang, B.T. Zhao, Y.Q. Wu, J. Yao. A comparison study on microwave-assisted extraction of Artemisia sphaerocephala polysaccharides with conventional method: Molecule structure and antioxidant activities evaluation. Int. J. Biol. Macromol. 45 (2009) 483-492.

[27] C. Yue, J. Chen, R. Hou, J. Liu, X. Li, Z. Gao, C. Liu, D. Wang, Y. Lu, H. Li, Y. Hu. Effects of selenylation modification on antioxidative activities of Schisandra chinensis polysaccharide. PloS One 10 (2015) e0134363.

[28] A. Hoz, A. Diaz-Ortiz, A. Moreno. Microwaves in organic synthesis. Thermal and non-thermal microwave effects. Chem. Soc. Rev. 34 (2005) 164-178. 
[29] J.L. Wang, W. Yang, J.C. Wang, X. Wang, F. Wu, J. Yao, J. Zhang, Z.Q. Lei. Regioselective sulfation of Artemisia sphaerocephala polysaccharide: Characterization of chemical structure. Carbohydr. Polym. 133 (2015) 320-327.

[30] X.B. Yang, X.D. Gao, F. Han, R.X. Tan. Sulfation of a polysaccharide produced by a marine filamentous fungus Phoma herbarum YS4108 alters its antioxidant properties in vitro. BBA-Gen. Subjects 1725 (2005) 120-127.

[31] Y. Peng, L.N. Zhang. Characterization of a polysaccharide-protein complex from Ganoderma tsugae mycelium by size-exclusion chromatography combined with laser light scattering. J. Biochem. Bioph. Meth. 56 (2002) 243-252.

[32] Y.Z. Tao, L.N. Zhang, C.K. Peter. Physicochemical properties and antitumor activities of water-soluble native and sulfated hyperbranched mushroom polysaccharides. Carbohydr. Res. 341 (2006) 2261-2269.

[33] B.T. Zhao, J. Zhang, J. Yao, S. Song, Z.X. Yin, Q.Y. Gao. Selenylation modification can enhance antioxidant activity of Potentilla anserina L. polysaccharide. Int. J. Biol. Macromol. 58 (2013) 320-328.

[34] J.L. Wang, S.F. Niu, B.T. Zhao, T. Luo, D. Liu, J. Zhang. Catalytic synthesis of sulfated polysaccharides. II: comparative studies of solution conformation and antioxidant activities. Carbohydr. Polym. 107 (2014) 221-231.

[35] Y.Y. Zhang, S. Li, L.N. Zhang. Aggregation behavior of triple helical polysaccharide with low molecular weight in diluted aqueous solution. J. Phys. Chem. B 114 (2010) 4945-4954.

[36] L. Kong, L. Yu, T. Feng, X. Yin, T. Liu, L. Dong. Physicochemical characterization of the polysaccharide from Bletilla striata: Effect of drying method. Carbohydr. Polym. 125 (2015) 
$1-8$.

[37] S. Zhang, S. Nie, D. Huang, Y. Feng, M. Xie. A novel polysaccharide from Ganoderma atrum exerts antitumor activity by activating mitochondria-mediated apoptotic pathway and boosting the immune system. J. Agr. Food Chem. 62 (2014) 1581-1589.

[38] P. Shao, X. Chen, P. Sun. Chemical characterization, antioxidant and antitumor activity of sulfated polysaccharide from Sargassum horneri. Carbohydr. Polym. 105 (2014) 260-269.

[39] D. Shang, Y. Li, C. Wang, X. Wang, Z. Yu, X. Fu. A novel polysaccharide from Se-enriched Ganoderma lucidum induces apoptosis of human breast cancer cells. Oncol. Rep. 25 (2011) 267-272. 


\section{Tables}

Table 1 Microwave assisted selenylation of ASP with the $\mathrm{HNO}_{3}$ concentration of $0.8 \%$ at $60^{\circ} \mathrm{C}$

\begin{tabular}{|c|c|c|c|c|c|c|}
\hline \multirow{3}{*}{ Sample } & Reaction & Microwave & $\mathrm{BaCl}_{2}$ & \multirow{3}{*}{ Yield (\%) } & Se content & \multirow{3}{*}{$\begin{array}{l}\text { Carbohydrate } \\
(\%)\end{array}$} \\
\hline & & & & & & \\
\hline & time $(\min )$ & power (W) & (g) & & $(\mu \mathrm{g} / \mathrm{g})$ & \\
\hline ASP & - & - & - & - & $-{ }^{a}$ & 90.3 \\
\hline $\mathrm{SeASP}_{\mathrm{MW} 1}$ & 15 & 300 & 1.654 & 93.1 & 115 & 80.7 \\
\hline $\mathrm{SeASP}_{\mathrm{MW} 2}$ & 30 & 300 & 1.650 & 86.4 & 141 & 79.6 \\
\hline $\mathrm{SeASP}_{\mathrm{MW} 3}$ & 60 & 300 & 1.652 & 89.3 & 111 & 84.4 \\
\hline $\mathrm{SeASP}_{\mathrm{MW} 4}$ & 120 & 300 & 1.651 & 72.1 & 264 & 85.4 \\
\hline $\mathrm{SeASP}_{\mathrm{MW} 5}$ & 300 & 300 & 1.650 & 94.9 & 235 & 83.2 \\
\hline $\mathrm{SeASP}_{\mathrm{MW} 6}$ & 480 & 300 & 1.613 & 91.3 & 179 & 77.3 \\
\hline $\mathrm{SeASP}_{\mathrm{MW} 7}$ & 120 & 300 & - & 66.9 & 257 & 80.6 \\
\hline $\mathrm{SeASP}_{\mathrm{cata}}{ }^{\mathrm{b}}$ & 360 & - & 1.652 & 69.9 & 969 & 69.8 \\
\hline SeASP & 120 & - & - & 79.8 & 79 & 86.8 \\
\hline
\end{tabular}

${ }^{\mathrm{a}}$ Not detected.

${ }^{\mathrm{b}}$ Data from our previous study [24]. The $\mathrm{HNO}_{3}$ concentration used in the synthesis of SeASP ${ }_{\text {cata }}$ was $0.7 \%$. 
Table $2 M_{\mathrm{W}}$, polydispersity (PD) and $d_{\mathrm{f}}$ values of ASP and SeASP $\mathrm{MW}_{\mathrm{MW}}$

\begin{tabular}{|c|c|c|c|c|c|}
\hline Samples & $\begin{array}{l}M_{\mathrm{W}} \times 10^{4} \\
(\mathrm{~g} / \mathrm{mol})^{\mathrm{b}}\end{array}$ & $M_{\mathrm{W}} / M_{\mathrm{n}}$ & Relation equation & $d_{\mathrm{f}}$ & $\begin{array}{l}\text { Solution } \\
\text { Conformation }\end{array}$ \\
\hline ASP & 7.348 & 3.184 & $\left\langle S^{2}\right\rangle_{z}^{1 / 2}=0.203 M_{w}^{0.35 \pm 0.027}$ & 2.86 & $\begin{array}{l}\text { between hard sphere } \\
\text { and random coil } \\
\text { (fully swollen) }\end{array}$ \\
\hline $\mathrm{SeASP}_{\mathrm{MW} 1}$ & 2.772 & 1.175 & $\left\langle S^{2}\right\rangle_{z}^{1 / 2}=1.11 M_{w}^{0.22 \pm 0.16}$ & 4.54 & hard sphere \\
\hline $\mathrm{SeASP}_{\mathrm{MW} 2}$ & 2.633 & 1.188 & $\left\langle S^{2}\right\rangle_{z}^{1 / 2}=3.85 M_{w}^{-0.61 \pm 0.40}$ & $-{ }^{a}$ & 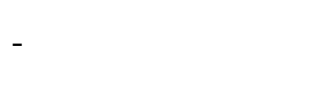 \\
\hline $\mathrm{SeASP}_{\mathrm{MW} 3}$ & 3.486 & 1.249 & $\left\langle S^{2}\right\rangle_{z}^{1 / 2}=-1.65 M_{w}^{0.77 \pm 0.33}$ & 1.30 & $\begin{array}{l}\text { between rigid rod } \\
\text { and random coil }\end{array}$ \\
\hline $\mathrm{SeASP}_{\mathrm{MW} 4}$ & 1.736 & 1.073 & $\left\langle S^{2}\right\rangle_{z}^{1 / 2}=-2.68 M_{w}^{0.68 \pm 0.39}$ & 1.47 & $\begin{array}{l}\text { between rigid rod } \\
\text { and random coil }\end{array}$ \\
\hline $\mathrm{SeASP}_{\mathrm{Mw}}$ & 2.752 & 1.100 & $\left\langle S^{2}\right\rangle_{z}^{1 / 2}=0.835 M_{w}^{0.44 \pm 0.15}$ & 2.27 & $\begin{array}{l}\text { between hard sphere } \\
\text { and random coil } \\
\text { (not swollen) }\end{array}$ \\
\hline $\mathrm{SeASP}_{\mathrm{MW} 6}$ & 4.667 & 2.241 & $\left\langle S^{2}\right\rangle_{z}^{1 / 2}=2.44 M_{w}^{-0.13 \pm 0.01}$ & - & - \\
\hline
\end{tabular}

${ }^{\mathrm{a}}$ Not detected 
Table 3. Effects of ASP and its selenized derivatives on cell apoptosis and cell cycle-phase distribution of $\mathrm{H} 1650$ cells after 48 hours treatment

\begin{tabular}{|c|c|c|c|c|c|}
\hline \multirow{2}{*}{ Samples } & \multirow{2}{*}{$\begin{array}{l}\text { Concentration } \\
(\mu \mathrm{g} / \mathrm{mL})\end{array}$} & \multirow{2}{*}{$\begin{array}{l}\text { Apoptosis } \\
(\%)\end{array}$} & \multicolumn{3}{|l|}{ Cell cycle (\%) } \\
\hline & & & $\mathrm{G}_{0} / \mathrm{G}_{1}$ & S & $\mathrm{G}_{2} / \mathrm{M}$ \\
\hline Control & 0 & 1.31 & $52.75 \pm 0.55$ & $35.97 \pm 0.23$ & $11.28 \pm 0.34$ \\
\hline \multirow{2}{*}{ ASP } & 100 & 2.29 & $63.88 \pm 0.10^{* *}$ & $27.06 \pm 0.13^{* *}$ & $9.06 \pm 0.06^{*}$ \\
\hline & 200 & 1.62 & $67.18 \pm 4.40^{*}$ & $25.90 \pm 4.17$ & $6.92 \pm 0.23^{* *}$ \\
\hline \multirow{3}{*}{$\mathrm{SeASP}_{\mathrm{MW} 1}$} & 100 & 5.41 & $65.50 \pm 1.21^{* *}$ & $25.42 \pm 0.93^{* *}$ & $9.08 \pm 0.27^{*}$ \\
\hline & & & & & \\
\hline & 200 & 3.04 & $58.90 \pm 8.17$ & $33.88 \pm 8.76$ & $7.22 \pm 0.60^{*}$ \\
\hline \multirow{3}{*}{$\mathrm{SeASP}_{\mathrm{MW}}$} & 100 & 2.70 & $63.05 \pm 0.93^{* *}$ & $26.72 \pm 1.53^{*}$ & $10.24 \pm 0.60$ \\
\hline & & & & & \\
\hline & 200 & 2.65 & $63.37 \pm 8.70$ & $29.69 \pm 9.96$ & $6.94 \pm 1.17^{*}$ \\
\hline
\end{tabular}

${ }^{*} p<0.05$ and ${ }^{* *} p<0.01$ compared with the control 


\section{Figure Captions:}

Fig. 1 FT-IR spectra (A) and ${ }^{13} \mathrm{C}$ NMR spectra of ASP (B), SeASP ${ }_{\mathrm{MW} 1}(\mathrm{C})$ and $\mathrm{SeASP}_{\mathrm{MW} 4}$ (D).

Fig. 2 SEC-MALLS chromatograms of ASP and SeASP $\mathrm{MW}_{\mathrm{MW}}$ (A) detected by laser light scattering photometry (B) Molar mass distribution analysis and (C) Log-log plot of $M_{\mathrm{W}}$ versus $\left\langle S^{2}\right\rangle_{z}^{1 / 2}$

Fig. 3 AFM images and section analysis of $\mathrm{SeASP}_{\mathrm{MW}}$ at the concentration of $10 \mu \mathrm{g} / \mathrm{mL}$ (A) $\mathrm{SeASP}_{\mathrm{MW} 6}(\mathrm{~B}) \mathrm{SeASP}_{\mathrm{MW} 3}$ and (C) SeASP $\mathrm{MW}_{4}$.

Fig. 4 AFM images and particle analysis of $\mathrm{SeASP}_{\mathrm{MW}}$ at the concentration of $1 \mu \mathrm{g} / \mathrm{mL}$ (A) $\mathrm{SeASP}_{\mathrm{MW} 6}$ and section analysis (B) SeASP $\mathrm{MW}_{3}$ and (C) SeASP $\mathrm{MW}_{\mathrm{MW}}$.

Fig. 5 Inhibition rates (A), cell apoptosis (B) and cell cycle proportions (C) of ASP, SeASP $\mathrm{MW1}_{\mathrm{M}}$ and $\mathrm{SeASP}_{\mathrm{MW}}$, against $\mathrm{H} 1650$ cells after incubated for $48 \mathrm{~h}$ in vitro. The inhibition rates were presented as mean values $(\mathrm{n}=3) .{ }^{*} p<0.05,{ }^{* *} p<0.01$ and ${ }^{* * *} p<0.001$ compared with the control. ${ }^{\#} p<0.05,{ }^{\#} p<0.01$ and ${ }^{\# \# \#} p<0.001$ compared with ASP. 
Figures
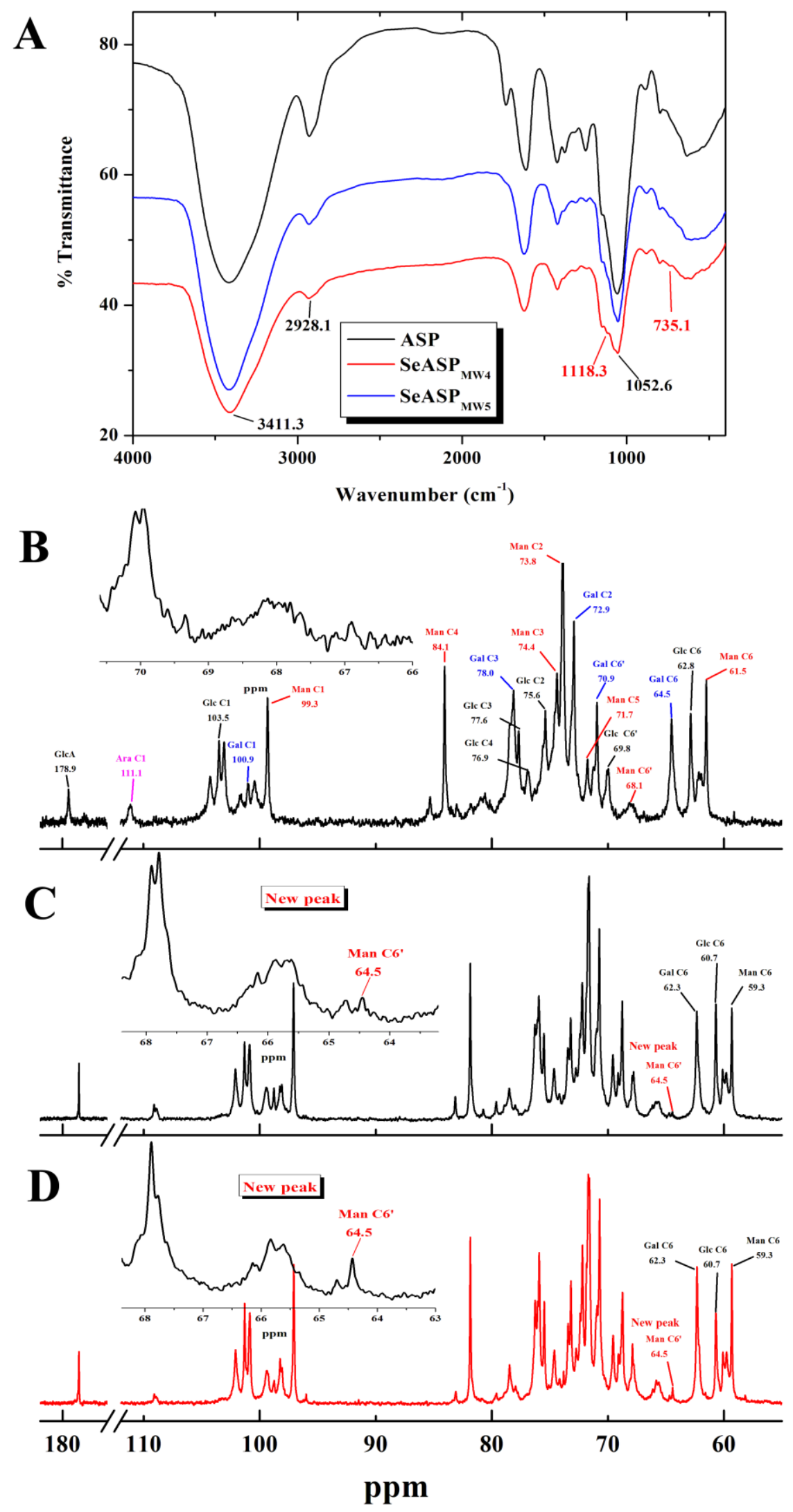
Fig. 1 FT-IR spectra (A) and ${ }^{13} \mathrm{C}$ NMR spectra of ASP (B), $\operatorname{SeASP}_{\mathrm{MW} 1}(\mathrm{C})$ and $\mathrm{SeASP}_{\mathrm{MW} 4}$ (D).
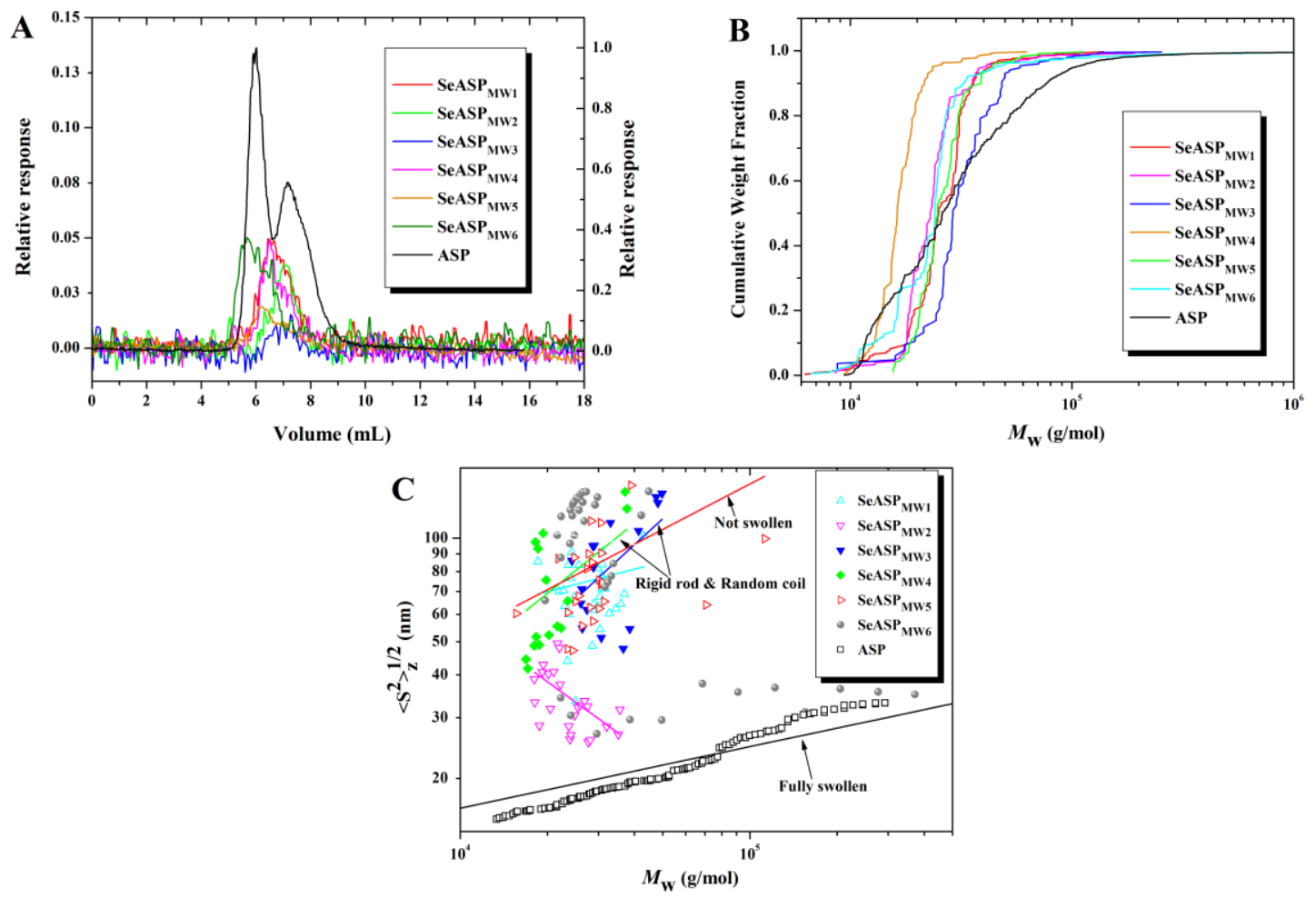

Fig. 2 SEC-MALLS chromatograms of ASP and SeASP $\mathrm{MW}_{\mathrm{M}}$ (A) detected by laser light scattering photometry (B) Molar mass distribution analysis and (C) Log-log plot of $M_{\mathrm{W}}$ versus $\left\langle S^{2}\right\rangle_{z}^{1 / 2}$. 

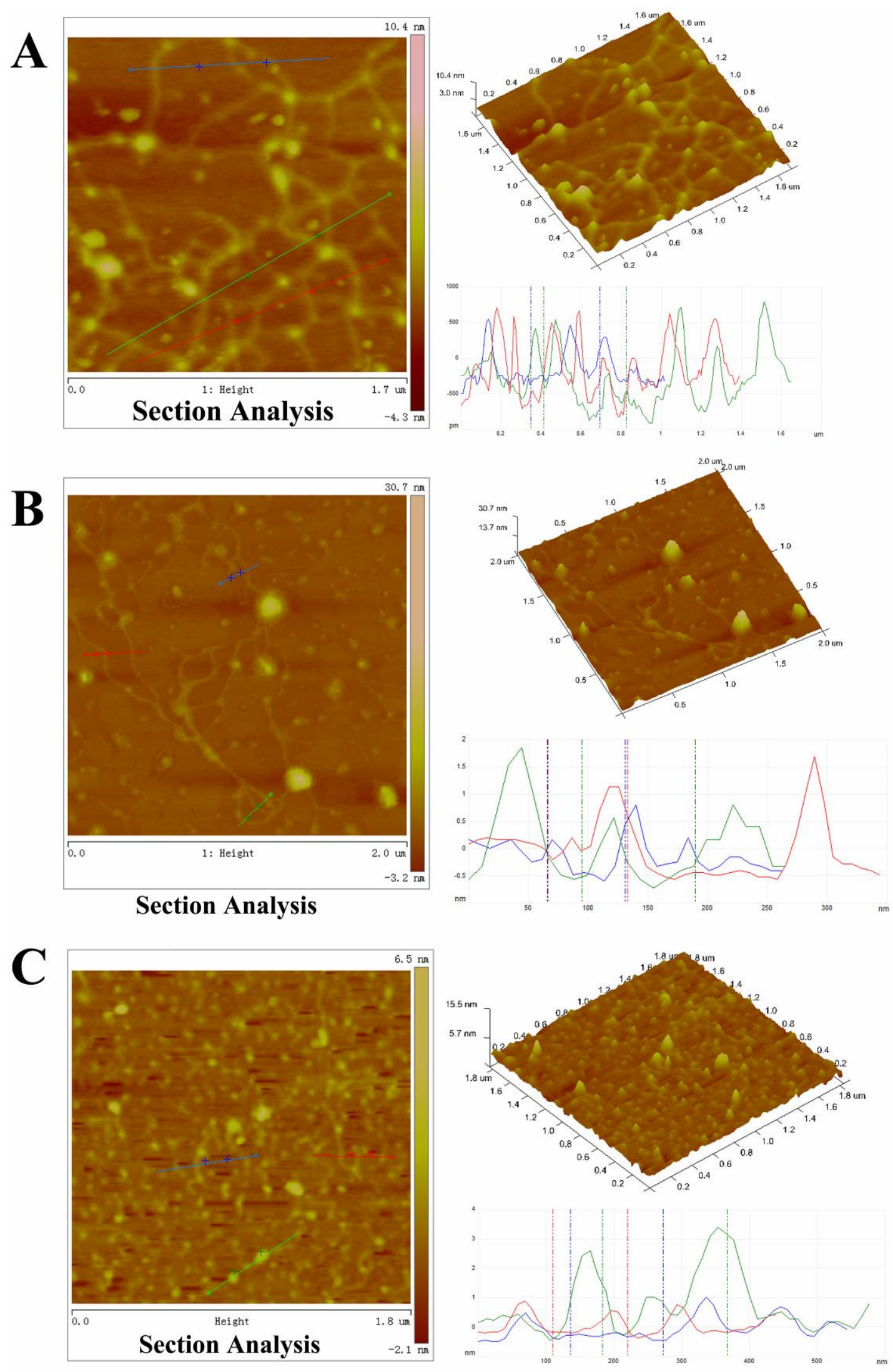

Fig. 3 AFM images and section analysis of $\mathrm{SeASP}_{\mathrm{MW}}$ at the concentration of $10 \mu \mathrm{g} / \mathrm{mL}$ (A)

$\mathrm{SeASP}_{\mathrm{MW}}$ (B) $\mathrm{SeASP}_{\mathrm{MW}}$ and (C) SeASP $\mathrm{SW}_{\text {MW }}$. 

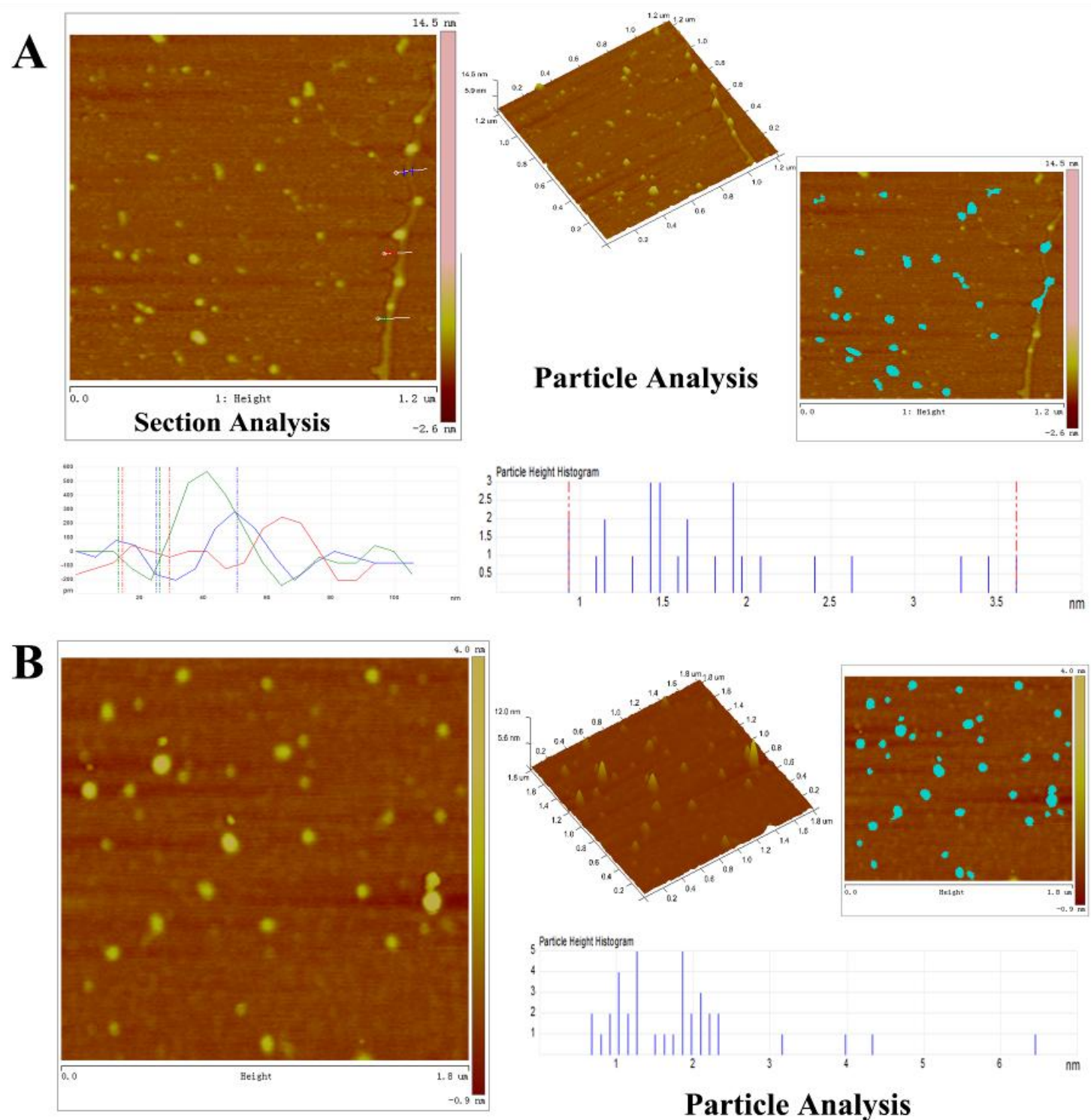

Particle Analysis
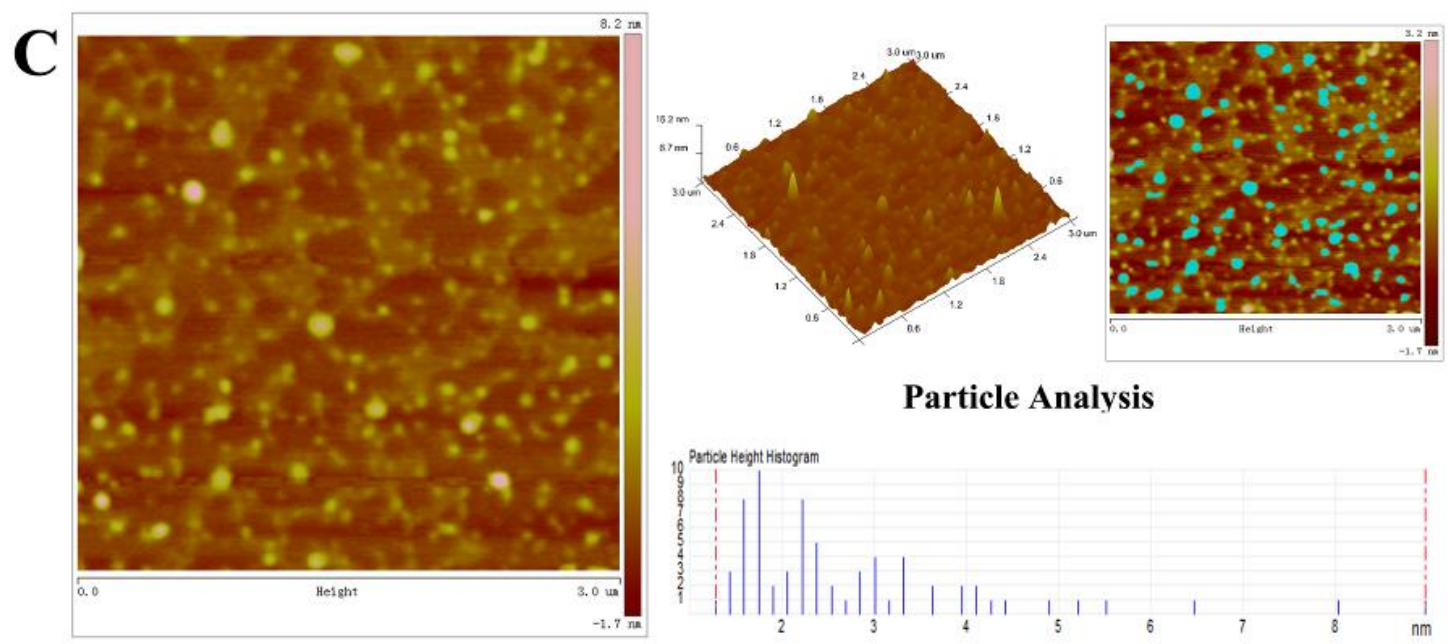

\section{Particle Analysis}

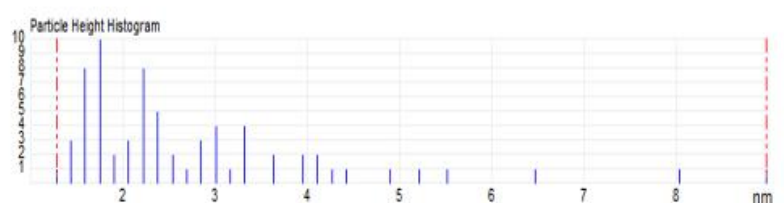

Fig. 4 AFM images and particle analysis of $\mathrm{SeASP}_{\mathrm{MW}}$ at the concentration of $1 \mu \mathrm{g} / \mathrm{mL}$ (A)

$$
\mathrm{SeASP}_{\mathrm{MW}} \text { and section analysis (B) SeASP} \mathrm{MW}_{3} \text { and (C) SeASP } \mathrm{MW}_{4} \text {. }
$$



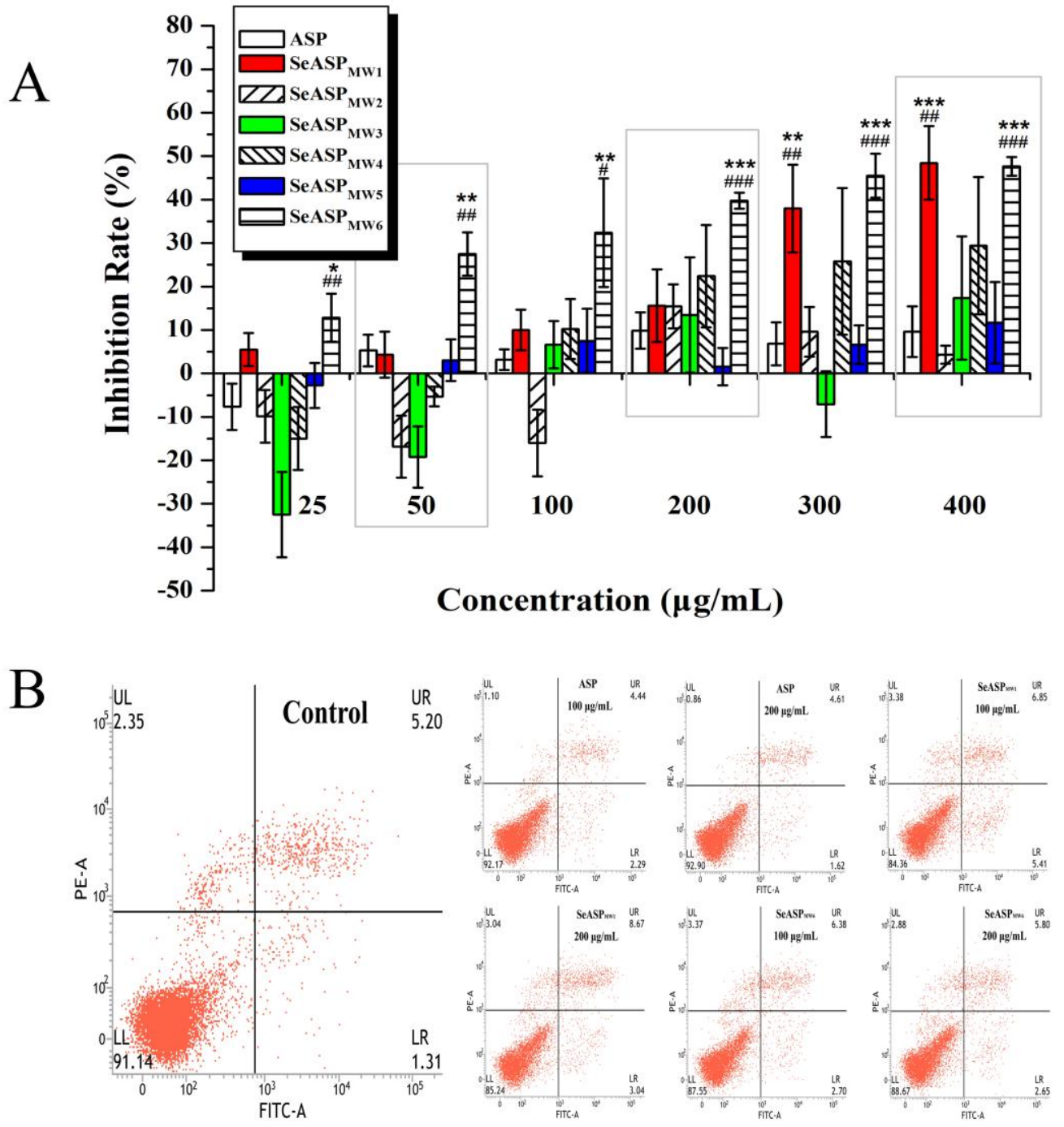

$\mathrm{C}$
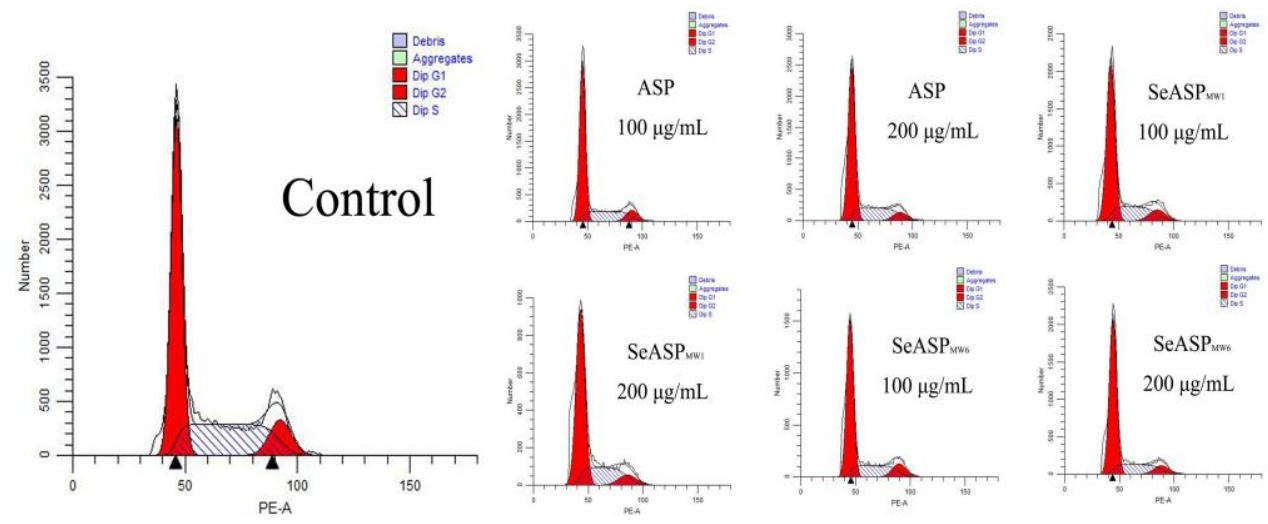

Fig. 5 Inhibition rates (A), cell apoptosis (B) and cell cycle proportions (C) of ASP, SeASP $\mathrm{MW}_{\mathrm{M}}$ and $\mathrm{SeASP}_{\mathrm{MW}}$, against $\mathrm{H} 1650$ cells after incubated for $48 \mathrm{~h}$ in vitro. The inhibition rates were presented as mean values $(\mathrm{n}=3) .{ }^{*} p<0.05,{ }^{* *} p<0.01$ and ${ }^{* * *} p<0.001$ compared with the control. ${ }^{\#} p<0.05,{ }^{\# \#} p<0.01$ and ${ }^{\# \# \#} p<0.001$ compared with ASP. 